\title{
The influence of heat treatments on order-disorder phenomena in a naturally occurring manganese-ferrite
}

\author{
Cherie R. Bluncson and B. J. Evans \\ University of Michigan, Department of Chemistry, Ann Arbor; Michigan 48109-1055
}

Naturally occurring samples of iwakiite, $\mathrm{Mn}_{1.1} \mathrm{Fe}_{1.9} \mathrm{O}_{4}$, have been annealed for 17 and $77 \mathrm{~h}$ at 1000 $\mathrm{K}$ in an investigation of order-disorder phenomena in $\mathrm{Mn}-\mathrm{Fe}$ oxide spinels. Two distinct magnetic hyperfine patterns, which correspond to Fe- and $\mathrm{Mn}$-rich phases, were observed in the ${ }^{57} \mathrm{Fe}$ Mössbauer spectra for the two annealed samples. While the spectrum of the Fe-rich phase corresponds to a magnetically and crystallographically highly ordered $\alpha-\mathrm{Fe}_{2} \mathrm{O}_{3}$-like phase, the Mn-rich phase exhibits considerable disorder, as indicated by very broad linewidths and a low value for $H_{\text {eff }}$. Annealing for longer periods of times leads to a considerable increase in the ordering of the Mn-rich spinel phase, as evidenced by the considerable narrowing of the lines, from $\mathrm{I}=2.40$ $\mathrm{mm} \mathrm{s}^{-1}$ to $\Gamma=1.17 \mathrm{~mm} \mathrm{~s}^{-1}$, and an increase in $H_{\mathrm{eff}}$ from 318 to $417 \mathrm{kOe}$ at $298 \mathrm{~K}$. The Fe-rich, $\alpha-\mathrm{Fe}_{2} \mathrm{O}_{3}$-like phase is not affected by further annealing, as expected. At $85 \mathrm{~K}$, the ${ }^{57} \mathrm{Fe}$ Mössbauer spectrum of the Mn-rich, spinel phase continues to exhibit rather broad lines, indicating the presence of significant cation disorder.

\section{INTRODUCTION}

The $\mathrm{Mn}_{x} \mathrm{Fe}_{3-x} \mathrm{O}_{4}$ system continues to present challenges concerning structure-property relationships, cation distributions, oxidation states, crystallographic order-disorder, and the electric and magnetic properties of oxide spinels exhibiting both variable cation distributions and mixed valence states. $^{1-4}$

Previous investigations of an iwakiite sample with the composition, $\mathrm{Mn}_{1.7} \mathrm{Fe}_{1.3} \mathrm{O}_{4}$, ${ }^{4}$ a naturally occurring mineral in the $\mathrm{Mn}_{3} \mathrm{O}_{4}-\mathrm{Fe}_{3} \mathrm{O}_{4}$ solid solution series, have demonstrated the existence of an unusually high degree of long-range order, as evidenced by a tetragonal distortion at a manganese content well below the limiting concentration observed in synthetic samples. In addition, results of ${ }^{57} \mathrm{Fe}$ Mössbauer spectroscopic measurements on this sample at $92 \mathrm{~K}$ in an applied field of $30 \mathrm{kG}$ have shown that $\mathrm{Fe}^{3+}$ occupies exclusively the octahedral sites. ${ }^{5}$ The occurrence of $\mathrm{Mn}^{3+}$ clustering and the resulting $\mathrm{Mn}$-rich and $\mathrm{Mn}$-poor (or Fe-rich) regions, have been suggested, on the basis of the observation of two $\mathrm{Fe}^{3+}$ species on a single magnetic sublattice. It was proposed that the two $\mathrm{Fe}^{3+}$ species correspond to those occupying $\mathrm{Mn}$-rich and $\mathrm{Mn}$-poor (or Fe-rich) regions of the crystal.

Further confirmation and delineation of the characteristics of the clustering suggested above has been sought in the study reported here by investigating the thermal stability of

TABLE I. ${ }^{57} \mathrm{Fe}$ hyperfine parameters at $298 \mathrm{~K}$ for iwakiite samples.

\begin{tabular}{ccccccc}
\hline \hline Sample & Subpattern & $\begin{array}{c}H_{\text {eff }} \\
(\mathrm{kOe})\end{array}$ & $\begin{array}{c}\Delta E_{Q} \\
\left(\mathrm{~mm} \mathrm{~s}^{-1}\right)\end{array}$ & $\begin{array}{c}\delta^{\mathrm{a}} \\
\left(\mathrm{mm} \mathrm{s}^{-1}\right)\end{array}$ & $\begin{array}{c}\mathrm{T} \\
\left(\mathrm{mm} \mathrm{s}^{-1}\right)\end{array}$ & $\begin{array}{c}\text { Area } \\
(\%)\end{array}$ \\
\hline $\begin{array}{c}\text { Iwakiite } \\
\text { Unannealed }\end{array}$ & $\cdots$ & 388 & -0.007 & 0.392 & 0.920 & 100 \\
Annealed $17 \mathrm{~h}$ & Fe rich & 500 & -0.109 & 0.390 & 0.458 & 38 \\
Annealed 17 h & Mn rich & 318 & -0.020 & 0.347 & 2.400 & 62 \\
Annealed 77 h & Fe rich & 513 & -0.104 & 0.373 & 0.343 & 30 \\
Annealed 77 h & Mn rich & 417 & -0.009 & 0.383 & 1.17 & 70 \\
\hline \hline
\end{tabular}

${ }^{\mathrm{a}}$ Isomer shifts are relative to Fe metal. the naturally equilibrated iwakiite and monitoring the local and long-range crystal/chemical structures as a function of laboratory-based heat treatments. It is expected that the degree of order observed in iwakiite does not correspond to thermodynamically stable structures at temperatures at which ionic motion is observable on laboratory time scales, and that mild heat treatments will bring about significant changes in both the local and long-range crystal/chemical structures.

\section{EXPERIMENT}

Pure iwakiite samples from the Gozaisho Mine, Iwaki City, Japan, were prepared by pulverizing whole-rock, hand specimens and grinding them with an agate mortar and pestle to a fine powder that passed a 400 mesh standard sieve. Iwakiite was isolated from the associated minerals by suspending the powder in organic liquids and separating the iwakiite by means of a manually manipulated rare-earth permanent magnet. This process was repeated until a pure spinel phase was obtained, as determined by $x$-ray diffractometry.

The chemical composition of the separated sample was determined by means of electron microprobe analysis.

The iwakiite sample was separated into two fractions; one fraction was annealed in an evacuated quartz ampoulc for $17 \mathrm{~h}$ at $1000 \mathrm{~K}$, and the remaining fraction was annealed under the same conditions for $77 \mathrm{~h}$. Both samples were cooled rapidly to $298 \mathrm{~K}$ following the heat treatments.

TABLE II. ${ }^{57} \mathrm{Fe}$ hyperfine parameters at $85 \mathrm{~K}$ for iwakiite samples.

\begin{tabular}{ccccccc}
\hline \hline Sample & Subpattern & $\begin{array}{c}H_{\text {eff }} \\
(\mathrm{kOe})\end{array}$ & $\begin{array}{c}\Delta E_{Q} \\
\left(\mathrm{~mm} \mathrm{~s}^{-1}\right)\end{array}$ & $\begin{array}{c}\delta^{\mathrm{a}} \\
\left(\mathrm{mm} \mathrm{s}^{-1}\right)\end{array}$ & $\begin{array}{c}\Gamma \\
\left(\mathrm{mm} \mathrm{s}^{-1}\right)\end{array}$ & $\begin{array}{c}\text { Area } \\
(\%)\end{array}$ \\
\hline $\begin{array}{c}\text { Iwakiite } \\
\text { Inannealed }\end{array}$ & $\cdots$ & 503 & 0.011 & 0.500 & 0.623 & 100 \\
Annealed 17 h & Fe rich & 525 & -0.097 & 0.486 & 0.449 & 41 \\
Annealed 17 h & Mn rich & 496 & -0.003 & 0.492 & 0.817 & 59 \\
Annealed 77 h & Fe rich & 529 & -0.050 & 0.460 & 0.384 & 24 \\
Annealed 77 h & Mn rich & 500 & -0.005 & 0.476 & 0.731 & 76 \\
\hline \hline
\end{tabular}

Isomer shifts are relative to $\mathrm{Fe}$ metal. 


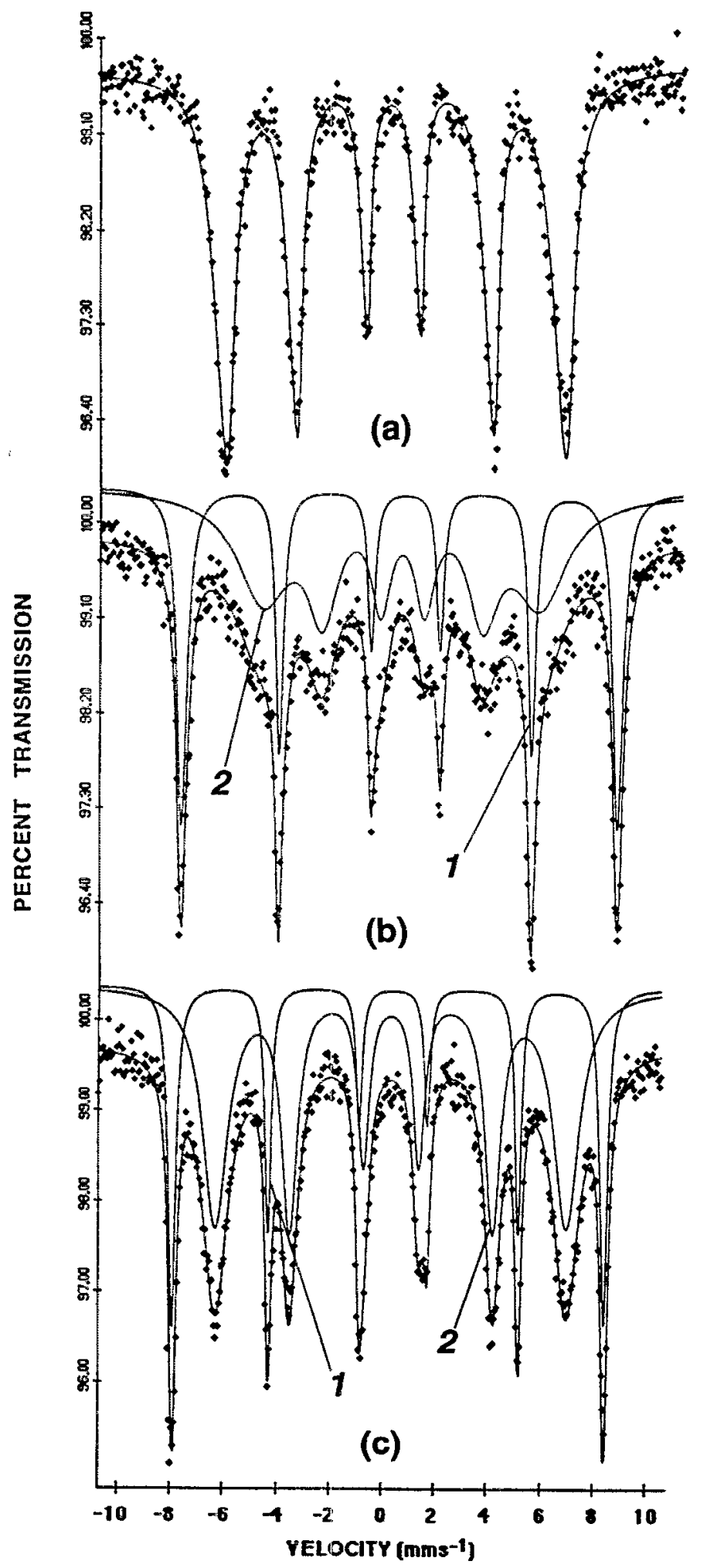

FIO. 1. ${ }^{5}$ Fe Mösbauer spectra $(298 \mathrm{k}$ ) of (a) unannealed iwakiite, (b) fwakite annealed for $17 \mathrm{~h}$ at $1000 \mathrm{~K}$, (c) iwakiite annealed for $77 \mathrm{~h}$ at 1000 $\mathrm{K}$ Ee-rich and $\mathrm{Mn}$-rich regions are represented by 1 and 2 , respectively.

${ }^{57} \mathrm{Fe}$ Mössbauer spectra were obtained in a transmission geometry using a 512 channel, microcomputer-configured multichannel scaler and a constant acceleration electromechanical drive. Spectra were obtained with the absorber at

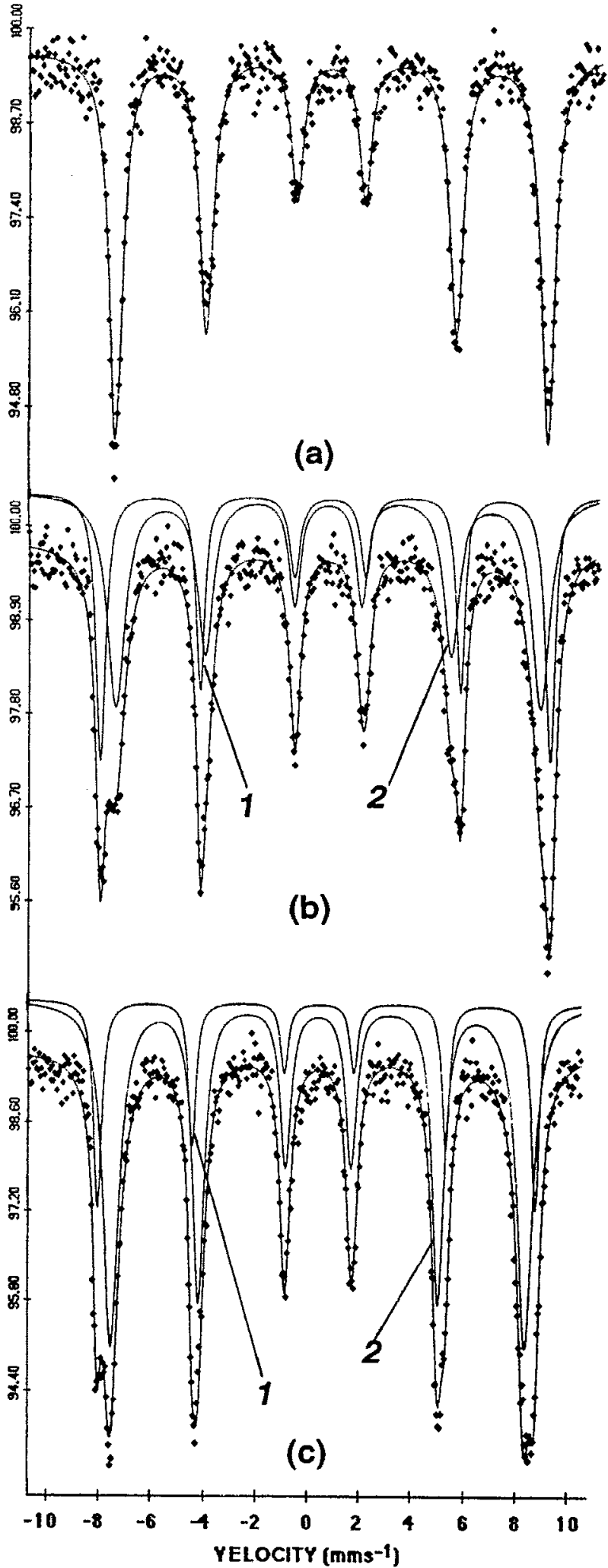

FIG. 2. ${ }^{57} \mathrm{Fe}$ Mössbauer spectra $(85 \mathrm{~K}$ ) of (a) unanncaled iwakiite, (b) iwakiite annealed for $17 \mathrm{~h}$ at $1000 \mathrm{~K}$, (c) iwakiite annealed for $77 \mathrm{~h}$ at $1000 \mathrm{~K}$ Fe-rich and Mn-rich regions are represented by 1 and 2 , respectively.

298 and $85 \mathrm{~K}$ in a vacuum cryostat. (See Tables I and II.) The source was always maintained at $298 \mathrm{~K}$. The spectra were analyzed by means of a previously described leastmean-squares fitting procedure. ${ }^{6}$ The filled dots in the spectra 
are the experimental data and the solid lines are the results of the fitting procedure.

\section{RESULTS AND DISCUSSION}

The chemical composition of the iwakiite sample used in this investigation was found to be $\mathrm{Mn}_{1.1} \mathrm{Fe}_{1.9} \mathrm{O}_{4}$. The manganese content is considerably lower than that of the previously studied sample, which had the composition $\mathrm{Mn}_{1,7} \mathrm{Fe}_{1.3} \mathrm{O}_{4}{ }^{4,5}$

The ${ }^{57} \mathrm{Fe}$ Mössbauer spectrum at $298 \mathrm{~K}$ for the unannealed sample shown in Fig. 1 was fitted to one six line pattern corresponding to a magnetic hyperfine field, $H_{\text {eff }}$, of $388 \mathrm{kOe}$. The samples annealed for 17 and $77 \mathrm{~h}$ were fitted to two six line patterns, where subpattern 1 with $H_{\text {eff }}=500$ kOe in Fig. 1(b), would be derived from the Fe-rich regions of the untreated iwakiite and subpattern 2 , with $H_{\text {eff }}=318$ $\mathrm{kOe}$, results from the $\mathrm{Mn}$-rich regions of the untreated iwakiite. The parameters corresponding to these fits are given in Tables I and II.

The spectrum in Fig. 1(b), representing the sample annealed for $17 \mathrm{~h}$ can be understood as consisting of two components: subpattern 2, which is attributed to a poorly crystalline $\mathrm{Mn}$-rich phase, as indicated by the large linewidths, $\Gamma=2.40 \mathrm{~mm} \mathrm{~s}^{-1}$, which has undergone phase separation from the unannealed iwakiite, and subpattern 1, which would correspond to a Fe-rich phase. From both the x-ray diffraction data and the ${ }^{57} \mathrm{Fe}$ Mössbauer parameters, it is clear that the phase giving rise to subpattern 1 is hematite, $\alpha-\mathrm{Fe}_{2} \mathrm{O}_{3}$. Upon further heating, as in the case of the $77 \mathrm{~h}$ anncal, there is considerable recrystallization and growth of the Mn-rich phase, giving rise to well-defined, long-range crystal/ chemical structures characteristic of the spinel structure. Clear evidence is provided for this by the remarkable decrease in the linewidths of subpattern 2 and the increase in the magnitude of $H_{\text {eff }}$ from 318 to $417 \mathrm{kOe}$ (cf. Table I). The width of the (404) line in the x-ray powder diffraction patterns undergoes a remarkable narrowing, in support of a decrease in the crystallographic disorder following the $77 \mathrm{~h}$ anneal at $1000 \mathrm{~K}$.

Spectra of the iwakiite samples at $85 \mathrm{~K}$ exhibit similar trends to those obtained at $298 \mathrm{~K}$, with the linewidths of subpattern 2, representing the Mn-rich phase, being broader for the sample annealed for $17 \mathrm{~h}$ than for the sample annealed for $77 \mathrm{~h}$ (cf. Table II).

A somewhat similar behavior has been observed for naturally occurring jacobsite, $\mathrm{MnFe}_{2} \mathrm{O}_{4}$, samples following heat treatments between 675 and $1175 \mathrm{~K}{ }^{7}$ The findings of this investigation are quite similar to those reported for jacobsite, ${ }^{7}$ inasmuch as there is a facile separation of a highly ordered hematite-like phase. The phase-separated spinel phase in the annealed jacobsite exhibits considerably less crystallinity and magnetic order than observed in the case of annealed iwakiites. We believe this difference is due to the greater degree of clustering in the iwakiite samples than in the jacobsites; there was no evidence for clustering in the unannealed jacobsites. ${ }^{7}$

\section{CONCLUSION}

Evidence for cation clustering and the occurrence of $\mathrm{Mn}$ - * rich and Mn-poor regions in naturally occurring $\mathrm{Mn}_{x} \mathrm{Fe}_{3-x} \mathrm{O}_{4}$ phases exhibiting high degrees of thermal equilibration has been provided by the ease with which such specimens undergo facile phase separations at temperatures well below those required for traditional solid state reactions. It is remarkable that the phase-separated, Fe-rich, $\alpha-\mathrm{Fe}_{2} \mathrm{O}_{3}$-like phase is well ordered, even for short periods of thermal annealing; long-range order is well established for both the crystal and magnetic structures, as indicated by the close agreement between the hyperfine parameters of this pattern at $298 \mathrm{~K}$ and those for a pure hematite. By way of contrast, the Mn-rich spinel phase exhibits considerable cation disorder, even for very long annealing periods, and, as a consequence, has values of $I_{\text {eff }}$ that arc much lower than those seen in synthetic $\mathrm{MnFe}_{2} \mathrm{O}_{4}$. The persistence of this disorder is due, most likely, to insufficient thermal energy and or time for the $\mathrm{Mn}$ and $\mathrm{Fe}$ ions to achieve a narrow range of local cation configurations. The relative magnitude of the magnetic hyperfine fields are consistent with this interpretation.

${ }^{1}$ F. K. Lotgering and A. M. Van Diepen, J. Phys. Chem. Solids 34, 1369 (1973).

${ }^{2}$ T. Yamanaka and M. Nakahira, Min. J. 7, 202 (1973),

${ }^{3}$ V. A. M. Brabers, Y. G. Proykova, N. Salemo, and T. E. Whall, J. Appl. Phys. 61, 4390 (1987).

${ }^{4}$ S. Matsubura, A. Kato, and K. Nagashima, Min. J. 9, 383 (1979).

${ }^{5}$ B. J. Evans, W. R. Dunham, C. Porter, S. M. Abernathy, and C. Bluncson, J. Appl. Phys. 63, 4133 (1988).

${ }^{6}$ HL. N. Ok and B. J. Evans, Phys. Rev. B 14, 2956 (1976).

${ }^{7}$ M. A. B. de Araujo, T. V. V. Costa, M. C. A. Lima, H. A. Maia, and V. W. Vieira, Phys. Scr. 40, 682 (1989). 